Elwood, P. C., Jacobs, A., Pitman, R. G., and Entwistle, C. C. (1964). Lancet, 2, 716.

Fulthorpe, A. J., Roitt, I. M., Doniach, D., and Couchman, K. (1961). f. clin. Paih., 14, 654 .

Holborow, E. J., Brown, P. C., Roitt, I. M., and Doniach, D. (1959). Brit. F. exp., Path., 40, 583 .

Jacobs, A. (1962). Brit. med. F., 2, 91.

- and Kilpatrick, G. S. (1964). Ibid., 2, 79.

Jones, R. F. McN. (1961). \%. Laryng., 75, 529.

Kelly, A. B. (1919). Ibid., 34, 285.

Markson, J. L., and Moore, J. M. (1962). Lancet, 2, 1240.
Paterson, D. R. (1919). 7. Laryng., 34, 289.

Taylor, K. B., Roitt, I. M., Doniach, D., Couchman, K. G., and Shapland, C. (1962). Brit. med. \%., 2, 1347

Vinson, P. P. (1922). Minn. Med., 5, 107

Waldenström, J., and Hallen, L. (1938). Acta med. scand., Suppl. No. 90 , p. 380 .

Witts, L. J. (1931). Guy's Hosp. Rep., 81, 193.

Wright, R. (1965). Amer. 7. Med., 38, 274.

Whitehead, R., Wangel, A. G., Salem, S. N., and Schiller, K. F. R (1966). Lancet, 1, 618

Wynder, E. L., and Fryer, J. H. (1958). Ann. intern. Med., 49, 1106.

\title{
Human Vibriosis: Indigenous Cases in England
}

\author{
W. D. WHITE,* M.B., B.S.
}

Brit. med. F., 1967, 2, 283-287

Vibriosis is a veterinary term covering a variety of disease in animals caused by vibrios. Vibrio infection in man conjures up a picture of cholera. Although not widely known, organisms similar to those causing vibriosis in animals also infect man. Cases of human vibriosis have been recorded in Europe and in the United States, but so far not in the British Isles. The condition is little known to clinicians, and unless borne in mind may be missed by the bacteriologist. The clinical picture is protean, the organisms are fastidious, and they may be difficult to maintain in culture. In human disease the vibrios present most commonly as Gram-negative spiral bacteria in blood cultures, and differ in other important respects from the cholera group. Their taxonomic position is not finally agreed upon. Two cases of human vibriosis have been seen in this hospital within a year, and it was felt that their description, accompanied by a brief review of human vibriosis, would be justified.

\section{Case 1}

A hotel pantryman, aged 58, attended the casualty department in August 1965 with a six-months history of mild abdominal pain and of vomiting small amounts of bile and blood-stained fluid. His appetite was good, and there was no loss of weight. While in the casualty department he vomited blood-stained fluid, and his blood pressure fell from 150/100 to 100/60 ; he became cold and clammy, and developed pulmonary oedema. He was admitted and treated initially as a case of coronary insufficiency and left heart failure, though the E.C.G. was not diagnostic.

Twenty-four hours after admission his temperature rose to $104^{\circ} \mathrm{F}$. $\left(40^{\circ}\right.$ C.). Septicaemia with peripheral circulatory failure and pulmonary oedema due to aspirated vomit were suspected. Blood cultures were taken, and he was given intravenous chloramphenicol and novobiocin $1.5 \mathrm{~g}$. of each daily. His blood urea at that time was $82 \mathrm{mg} . / 100 \mathrm{ml}$., and barium swallow showed a hiatus hernia and a possible acute duodenal ulcer. On the third day he was found to be anuric. His blood urea rose to $285 \mathrm{mg} . / 100 \mathrm{ml}$. and peritoneal dialysis was begun on the fourth day. On the fifth day he had a macular rash on his chest, back, and shoulders. The blood culture taken on the first day was found to be positive with an unidentified anaerobic Gram-negative bacterium. Fourteen subsequent cultures of blood or bone marrow were negative. Further bacteriological findings are described below.

The main findings and events are recorded along with the temperature in Fig. 1. The patient remained ill, and required peritoneal dialysis for two and a half weeks before diuresis set in. Throughout this time the vomiting continued. By the tenth day he had ankle oedema due to a combination of heart failure, venous thrombosis, and a low serum albumin. The initial antibiotics were given for only two days; on the seventh day he was started on

* Lecturer, Department of Medical Microbiology, St. George's Hospital Medical School, London S.W. cloxacillin $2 \mathrm{~g}$. daily, and the next day chloramphenicol $1 \mathrm{~g}$. daily was added to this. These antibiotics were continued for 14 and 9 days respectively without apparent effect on his temperature. On the 27th day he had a large haematemesis, requiring a transfusion of 4 pints (2.3 litres) of blood. He developed a transient diastolic murmur, and the E.C.G. now showed signs of subendocardial infarction.

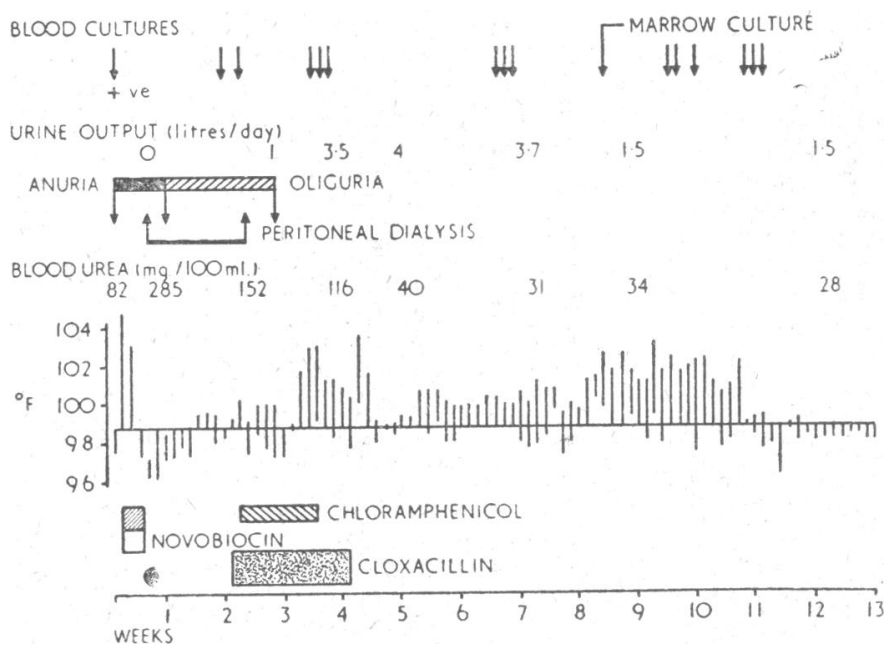

Fig. 1.-Case 1. Temperatures are recorded as a vertical line showing range of temperature for each 24 hours. Dosage of antibiotics are in text Positive sign under arrow indicates a positive culture.

Despite continuing fever his condition improved. After 11 weeks of illness the pyrexia subsided, and two weeks later he was well enough for discharge. After convalescence he returned to work and remained well.

\section{Laboratory findings}

The first blood culture was taken on the day after admission before chemotherapy was started. Two bottles were used for blood cultures, one containing $50 \mathrm{ml}$. of nutrient broth and the other $30 \mathrm{ml}$. of thioglycollate broth. The first received $5 \mathrm{ml}$. and the second $3 \mathrm{ml}$. of blood. The set was incubated at $37^{\circ} \mathrm{C}$. with tightened caps and without added carbon dioxide. No visible change occurred in either bottle, though the organism was recovered from both when they were subcultured after two days. Growth occurred in anaerobic subcultures on blood agar after two days' incubation and was almost overlooked. It appeared as a thin transparent effuse growth over the inoculated area. On further incubation the growth became thicker and more opaque with a metallic surface sheen, and the edge began spreading. The medium under the growth took on a coral pink discoloration. Further anaerobic subcultures took three 
to four days to give isolated tiny colonies. No growth occurred in aerobic cultures even with added $3 \%$ carbon dioxide (candle jar) after seven days.

The organism was difficult to stain. The Gram stain suggested a tiny coccobacillus. With methylene blue, elongated pale-staining forms could be seen together with densely staining granules. The impression of a coccobacillus was due to the latter. Staining with hot carbolfuchsin revealed slender corkscrew-shaped organisms. The organism was not acid-fast.

Dark-ground examination of fluid from the original blood-culture bottles showed a small curved rod with the rapid darting motion of a vibrio. Many forms appeared as spirals with three to four turns. These moved more sluggishly, and appeared also to rotate around their long axis. There was no lateral flexion; the spirals appearing rigid.

Both negatively stained and shadowed preparations from the subculture were examined by electron microscopy. The organism appeared spiral-shaped, often with two to three turns. The total length varied from 1.5 to 5 microns and the thickness from 0.35 to 0.45 microns. The majority of the organisms were amphitrichate (Fig. 2). The flagella were sheathed, the sheath being continuous with the bacterial cell wall, which presented a honeycomb-like surface pattern (Figs. 3 and 4). The flagellum often seemed to be inserted deeply into the organism (Fig. 4), and the insertion at times presented in the form of a hook (Figs. 4 and 7). Some of the flagella had a basal body at their origin (Figs. 5 and 7). Organisms with flagella only partially sheathed (Fig. 6) or with the flagellum originating from a coccoid body (Fig. 7) are also illustrated. All these features fit the description of the ultrastructure of Vibrio fetus (Ritchie et al., 1966), except that flagellar sheathing was not described.

The organism was oxidase-positive and catalase-negative. With a disc diffusion method on blood agar the organism was found to be sensitive to cephaloridine, novobiocin, streptomycin, tetracycline, chloramphenicol, neomycin, and the sulphonamides, but resistant to penicillin and cloxacillin.

Six young white mice were injected intraperitoneally with $0.5 \mathrm{ml}$. of the blood-culture material and all the animals survived the infection. No vibrios were recovered from peritoneal washings or blood of the animals over a 10-day period, nor from the internal organs when the animals were killed. That the injected material still contained live organism was proved by subsequent successful subculture.

For a time maintenance of the strain proved increasingly difficult, and early on there was insufficient material for serological tests. After some weeks of effort reasonable growth was obtained from the original blood cultures on a chocolate agar containing defibrinated horse blood and washed agar. The organism still grew slowly as a strict anaerobe, taking four to five days to give transparent pinheadsized colonies. In areas of confluent growth on prolonged incubation it showed the metallic sheen and the coral-pink discoloration of the medium seen with the original subcultures. The organism was motile, oxidase-positive, and catalase-negative, and the antibiotic sensitivity pattern had not changed. By light microscopy its morphology was the same, but under the electron microscope, though still amphitrichate, its flagella were unsheathed and the surface pattern of the organism was lost. At this stage it closely resembled the published appearances of $V$. fetus (Rhoades, 1954 ; King, 1962 ; Ritchie et al., 1966). The organism was now found to be autoagglutinable, making serological investigation with the patient's serum impossible.

Suspensions were prepared from three strains of $V$. fetus of human origin, one of animal origin, and one strain of $V$. bubulus. All five were good antigens, and showed high-titre agglutination with the homologous antisera prepared in rabbits. Specimens of serum obtained from the patient throughout the course of his illness failed to agglutinate any of these suspensions.

\section{Case 2}

A man of 70 was admitted to hospital in June 1966. His notes showed a history of achalasia and megaoesophagus, with haematemesis from oesophageal ulceration in 1961 and 1962. Three weeks before admission his left elbow became painful and 10 days later his knees also, so that he was unable to walk. On examination

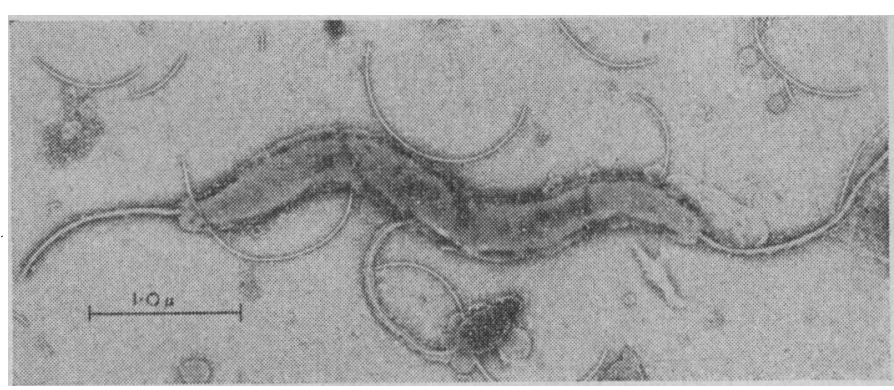

FIG. 2

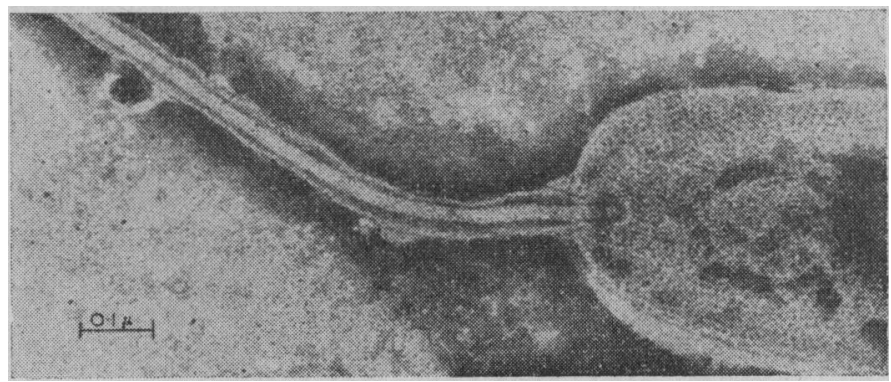

FIG. 3

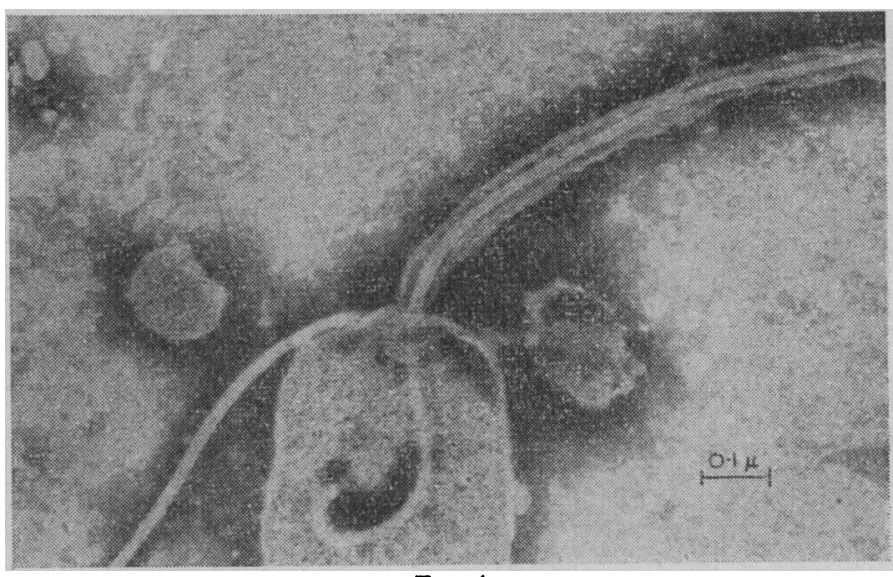

FIG. 4

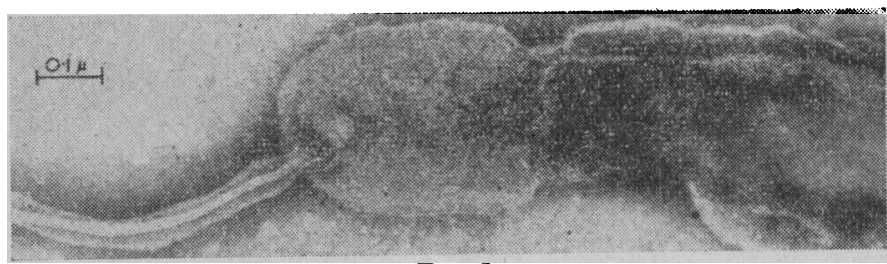

FIG. 5

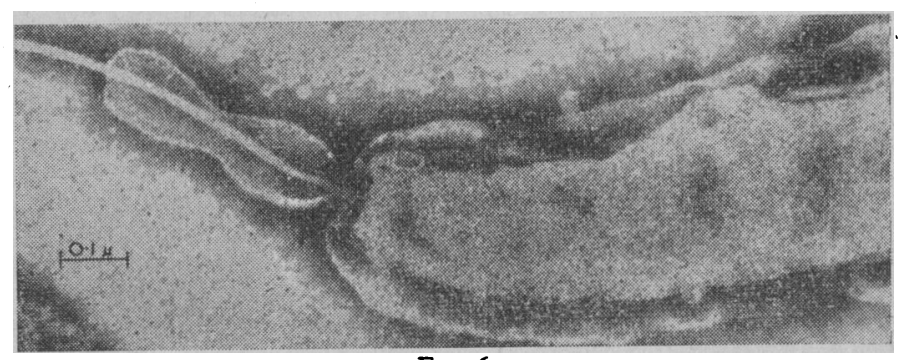

FIG. 6

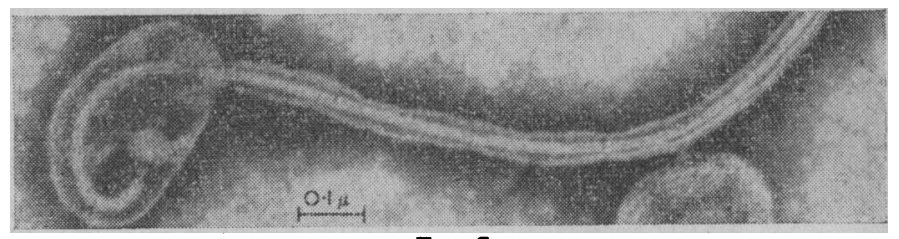

Fig. 7

FIGs. 2-7.-Case 1. Showing organisms with sheathed flagella and other features mentioned in tert. 
he had a temperature of $101.6^{\circ} \mathrm{F} .\left(38.7^{\circ} \mathrm{C}\right.$.), effusions into the left elbow and both knees, and a systolic ejection murmur.

Aspiration of the knee joints yielded cloudy yellow fluid containing numerous polymorphonuclear leucocytes. No organisms were seen on direct smear and routine cultures were sterile. No acid-fast bacilli were found. He had a hypochromic anaemia with Hb $51 \%$, M.C.H.C. $29 \%$, and a W.B.C. count of $17,800(89 \%$ neutrophils with a shift to the left). Blood culture on the day of admission was sterile. He was transfused with packed cells and given penicillin and ampicillin. He improved, and by the 12th day his joints were free of fluid and the knees had 90 degrees of movement without pain. As he still had an irregular pyrexia, further blood cultures were taken. By the 14th day he had a macular rash, and his penicillin was stopped. The second blood culture was found to be positive with an anaerobic vibrio. He was started on chloramphenicol. The pyrexia settled, but his condition deteriorated. His blood urea, which was raised on admission and had subsequently fallen, rose again, and he died on the 28th day. A summary of the clinical course is shown in Fig. 8.

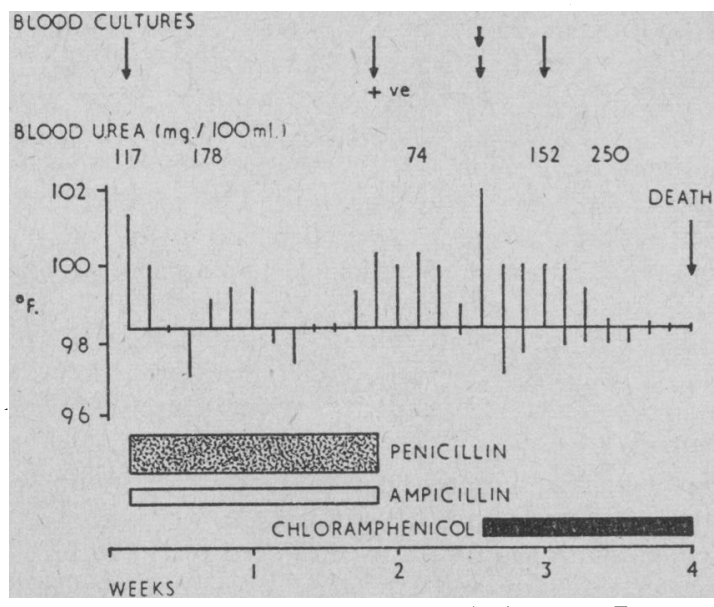

Fig. 8.-Case 2. Temperature recorded as in Fig. 1. Dosage of antibiotics: benzylpenicillin 1 mega unit 6-hourly (intramuscularly); ampicillin 0.5 g. 6-hourly orally; chloramphenicol 0.5 g. 6 -hourly (intramuscularly). Positive sign over arrow indicates a positive culture.

At post-mortem examination the oesophagus was grossly dilated and showed mucosal ulceration. There were no other relevant findings. Cultures taken from prepuce, prostate, testes, meninges, bone marrow, and gum margins failed to yield vibrios.

\section{Laboratory findings}

The vibrio isolated from this case grew anaerobically on first isolation. However, it grew more rapidly than that from Case 1, forming pinpoint colonies in 24 hours. The growth had a slight buff colour in confluent areas and showed the coral-pink discoloration of the chocolate agar beneath. It did not develop a metallic sheen, and only some subcultures on moist plates showed a tendency to spread. This strain was not difficult to maintain in subculture. The organism stained readily with Gram stain, and showed characteristic comma forms and a few spirals. In wet preparations they had the darting motion of a vibrio. Under the electron microscope there were amphitrichate comma and " $S$ " forms, but no sheath was present on the flagella (Fig. 9).

The organism was sensitive to streptomycin, chloramphenicol, tetracycline, erythromycin, sulphonamides, neomycin, and colistin, and resistam to penicillin and cloxacillin, a disc diffusion method being used. The organism was oxidase-positive, showed very poor catalase activity, was indole-negative, and did not produce hydrogen sulphide. It did not utilize citrate or liquefy gelatin, and was ureasenegative by Elek's (1948) method. It did not form acid or gas from glucose, lactose, sucrose, mannitol, maltose, or sylose after 10 days. In agar shake cultures in tightly capped bottles the organism grew as a band $1 \mathrm{~mm}$. wide, $5 \mathrm{~mm}$. below the surface. It would not grow on plate cultures in a candle jar but would in an anaerobic jar with $10 \%$ oxygen and $10 \%$ carbon dioxide added. The organism grew well at $42^{\circ}$ and $37^{\circ} \mathrm{C}$, poorly at $30^{\circ} \mathrm{C}$, , and not at $25^{\circ} \mathrm{C}$. Two sera from the patient were available for testing, one taken on the 12th day after admission and one at necropsy. Neither agglutinated a suspension of the vibrio isolated from the patient's blood culture, nor was the organism agglutinated by sera made in rabbits against a human strain of $\boldsymbol{V}$. fetus or against a strain of $V$. bubulus. No antiserum to "related vibrios" was available for testing.

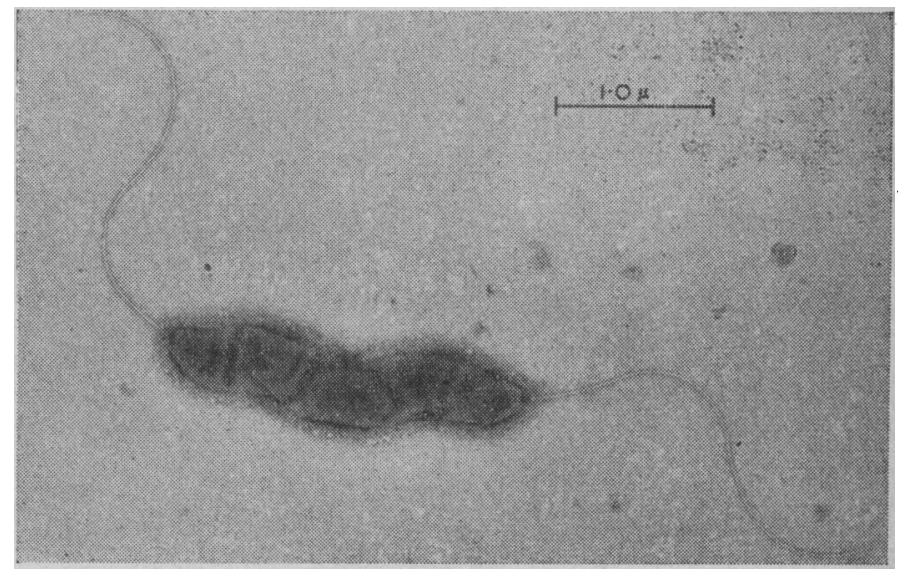

FrG. 9.-Case 2. Showing flagellate organism without sheaths.

\section{Discussion}

\section{Organisms causing vibriosis}

The first member of this group was described in 1913 by MacFadyean and Stockman as the cause of infectious aborption of ewes. They also observed outbreaks in cattle, as did Smith (1918). Later Smith and Taylor (1919) named the organism Vibrio fetus. $V$. fetus is now recognized as the cause of a venereal disease of cattle, the bull acting as a silent carrier, and gives rise to placental infection of the cow. The similar disease in sheep due to $V$. fetus appears to be contracted by ingestion. The other main forms of animal vibriosis are winter diarrhoea of cattle, $V$. jejuni (Jones and Little, 1931); a diarrhoeal condition of pigs, $V$. coli (Doyle, 1948); and an infectious avian hepatitis, unnamed species (Peckham, 1958). All these organisms are microaerophilic vibrios related to $V$. fetus. A further, non-pathogenic anaerobic species, $V$. bubulus, has been isolated from the genital tracts of cattle.

King (1957, 1962) recognizes three closely related but serologically distinct species-V. fetus, "related vibrio," and $V$. bubulus-the first two being associated with disease in man. These organisms are Gram-negative curved slender rods frequently showing spiral forms, actively motile, being monotrichate or amphitrichate. They are all oxidase-positive and are relatively inactive biochemically, but may be differentiated as in the Table. Of 71 strains of human origin which were isolated in different parts of the world 60 were $V$. fetus and 11 were " related vibrios" (King, 1962, 1965).

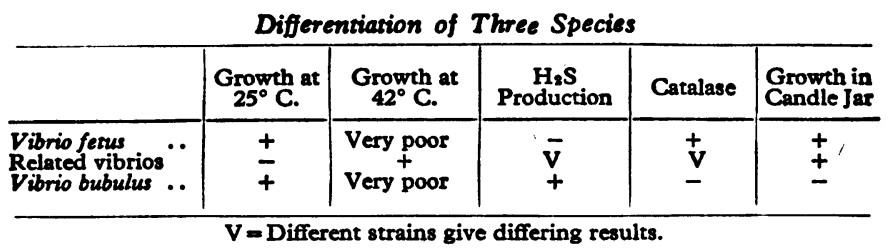

The genus Spirillum is now classified as lophotrichate and Vibrio as monotrichate or amphitrichate (Wilson and Miles, 1964). The microaerophilic vibrios are easily distinguishable from the classical aerobic vibrios ( $V$. cholerae, $V$. metschnikovi) biochemically and antigenically. Furthermore, Loesche et al. (1965) quote Sebald and Veron as stating that the deoxyribonucleic acid base composition of $V$. bubulus and $V$. fetus differs from that of the cholera group, and on the strength of this they suggested that the former should be included in a new 
genus, Campylobacter. At present the classification, terminology, and gaseous requirements of . the organisms causing vibriosis are confused (Kiggins and Plastridge, 1956; King, 1957, 1962 ; Lecce, 1958 ; Park, 1961 ; Ringen and Frank, 1958 ; Fletcher and Plastridge, 1964 ; Loesche et al., 1965). However, a $10 \%$ concentration of carbon dioxide with microaerophilic conditions appears to be beneficial for the growth of all strains. Antigenically the various groups or species of vibrios appear to be heterogenous (Moore, 1954 ; King, 1957 ; Reich et al., 1961).

\section{Clinical forms of human vibriosis and epidemiology}

Levy (1946) was the first to suggest that an organism resembling $V$. fetus could cause human disease. He investigated an institutional outbreak of gastroenteritis and isolated a vibrio from the blood cultures of a third of a selection of these cases. King (1957) recorded four cases of bloody diarrhoea in infants and a further case in a chicken-farmer, from all of whom vibrios were isolated only by blood culture. At post-mortem examination on the farmer jejunal lesions similar to those seen in cattle with winter scours were found. Wheeler and Borchers (1961) reported a further four cases in young children, three with positive blood cultures, the fourth being diagnosed serologically. Middelkamp and Wolf (1961) recorded an isolation from a child with bloody diarrhoea, and Mandel and Ellison (1963) from an adult The majority of recorded cases were apyrexial and the stools dysenteric in type. In all cases other human enteric bacterial pathogens were excluded, and no investigator succeeded in isolating the vibrio from the stool.

$V$. fetus infection associated with pregnancy was first reported by Vinzent and reviewed by him in 1949. Three cases were described, all the women survived, two aborted and one had a live birth, and all were diagnosed by blood culture. Hood and Todd (1960) reported a further human case with abortion, the organism being isolated from the placenta and foetal brain. An earlier report by Curtis (1913) may well have been vibriosis. $\mathrm{He}$ noted flagellate comma-shaped and spirillar organisms in the uterine discharges of two cases of puerperal infection. Cultivation of the uterine discharge from one showed the organism to be a strict anaerobe.

Pyrexia without localizing signs was the form of presentation in Spink's (1957) case. The patient had a history of proved brucellosis, but a vibrio was grown in a blood culture taken during what was at first thought to be a relapse of his undulant fever. Jackson et al. (1960) recorded a case of recurrent pyrexia with repeated isolation of the same vibrio by blood culture. Darrell et al. (1967), in this country, obtained a vibrio by blood culture from an Egyptian with a complex febrile infection.

Pyrexial illness followed by localization of infection is not uncommon. Meningitis has been reported by Eden (1962) in a neonate, by Robins et al. (1962) and Collins et al. (1964) in adults with isolation of the vibrio from cerebrospinal fluid, subdural fluid, and by blood culture. Burgert and Hagstrom (1964) reported meningoencephalitis in two neonates who died, with isolation of $V$. fetus from the cerebrospinal fluid of one during life and from the brain of both at necropsy. Subacute bacterial endocarditis has been reported in five cases, three in reports from France and two in the U.S.A. (Kilo et al., 1965); Loeb et al. (1966) reported two further cases. Septic arthritis has been reported twice-once by Kilo et al. (1965), with isolation of a vibrio from both blood and joint luid, and once by King and Bronsky (1961), with isolation from the joint only. Three cases of extensive thrombophlebitis in adults with positive blood cultures were reported by Kahler and Sheldon (1960). A single case of laboratory infection was recorded by Ward (1948).

The type of vibrio isolated in all the recorded cases of diarrhoeal disease was a "related vibrio," except in the case of Mandel and Ellison (1963), which was due to V. fetus. By contrast, $V$. fetus was isolated from all the other forms of human vibriosis, again with one exception-the isolation by Darrell et al. (1967) of a related vibrio. Nevertheless, it is important to note that the diagnosis was most often established only by means of blood culture, irrespective of the exact species involved and of the clinical syndrome presented.

Few investigators have found agglutinating antibodies to vibrios in the patient's sera. Hood and Todd (1960) showed a titre of 640 to the homologous $V$. fetus strain in their patient and a titre of 320 in the husband, and high titres have been reported by Kilo et al. (1965) and by Jackson et al. (1960). Wheeler and Borchers (1961) recorded values of 64 to 280 in their cases against an antigen made from one of their isolates of related vibrios.

The epidemiology of human cases is not yet understood. Levy (1946) incriminated a milk supply, while Hood and Todd (1960) proposed a venereal route. Close contact with animals has often been sought but seldom established. Thus sources other than animals should be sought, and an endogenous origin might be considered. Curtis (1913) noted "spirilla" in the human vagina; an anaerobic strain isolated from a case of puerperal infection by him was later classified as a vibrio (V. mulieris) by Prévot (1948). Moore (1954) also isolated anaerobic vibrios from the human vagina. Hood and Todd (1960) could still isolate $V$. fetus two and a half months post partum from their patient's cervix. V. sputorum (an anaerobic organism found in the mouth) (Tunnicliff, 1914; Prévot, 1940 ) differs in only very minor characters from $V$. bubulus (Loesche et al., 1965). King (1957) mentions three cases of vibriosis in patients who had had recent dental extractions or root disease.

There are few reports of antibiotic sensitivity of the organisms. Tetracycline, chloramphenicol, erythromycin, and the streptomycin group have usually been found to be effective in vitro. Penicillin and novobiocin were not (Kahler and Sheldon, 1960 ; King and Bronsky, 1961 ; Collins et al., 1964 ; Kilo et al., 1965).

\section{Present cases}

Both our cases presented as a pyrexial illness in which an unusual spiral organism was revealed by blood culture. The main problem was to identify the organism and to establish its relevance to the clinical syndrome-difficulties shared by others encountering human vibriosis (Spink, 1957; Wheeler and Borchers, 1961 ; Darrell et al., 1967).

The motile spiral organism from our first case was clearly not Borrelia, Leptospira, or Treponema, and at first was thought to be a spirillum. Because of the patient's possible occupational contact with rats, rat-bite fever was considered, but the typical clinical features of sodoku were absent. Moreover, since Spirillum minus is lophotrichate, is pathogenic to mice, and is generally believed not to grow on blood agar, it was excluded.

Electron microscopy provided the best way to a morphological diagnosis, and these features, together with the other laboratory findings, conformed in general to those described by King (1957) for organisms causing human vibriosis. Using her criteria, our first strain was thought to be most probably $V$. bubulus, but unfortunately it died out before complete identification. The second strain was identified as a microaerophilic related vibrio; a subculture was sent to Dr. King, who confirmed the identification.

For the clinical pathologist we would stress the importance of blood cultures in establishing the diagnosis. From our own experience and that of others it was noted that plate subcultures may be slow to grow and must be maintained long enough in the right gaseous environment, they may be difficult to see, and some strains tend to die out on further subculture (Smith, 1918 ; Levy, 1946 ; Moore, 1954 ; Wheeler and Borchers, 1961). In 
an attempt to avoid loss of our second strain we froze some aliquots of the original blood cultures at $-70^{\circ} \mathrm{C}$., and found on later examination that the organisms had survived.

\section{Summary}

Two cases of human vibriosis, the first to be recorded in Britain, are described. One of the vibrios isolated was a strict anaerobe, a type not previously recorded as a human pathogen. The condition should be considered whenever a pyrexia of unknown origin is being investigated, and is most likely to be diagnosed if blood cultures are taken. The organisms causing human vibriosis are related to those causing vibriosis in animals and distinct from those causing cholera in man. Non-cholera vibrio infection in man (human vibriosis) may present as a dysentery-like condition or as a pyrexial bacteraemic illness with or without localization of infection. Localization is most likely to occur in the meninges, synovial membranes, valvular endocardium, and, in pregnant women, in the foetus and foetal membranes and placenta.

I wish to thank Dr. K. Robson and Dr. T. Pilkington for permission to use their clinical notes and for access to their patients. Also Dr. Kingsley Smith for the electron microscopic studies and Miss H. Laderach for technical assistance. Special thanks are due to Dr. E. O. King, of the Communicable Disease Centre, Atlanta, Georgia, for advice, for the strains of $V$. fetus and $V$. bubulus used to prepare antisera, and for confirming the identity of the organism isolated in Case 2. Finally, I wish to thank Professor S. D. Elek and Dr. G. R. F. Hilson for advice in writing the paper.

\section{REFERENCES}

Burgert, W., and Hagstrom, J. W. C. (1964). Arch. Neurol. (Chic.), 10, 196.

Collins, H., Blevins, Ann, and Benter, Eleanor (1964). Arch. intern. Med., 113, 361

Curtis, A. H. (1913). F. infect. Dis., 12, 165
Darrell, J. H., Farrell, B. C., and Mulligan, Rosemary A. (1967). Brit. med. 7., 1

Doyle, L. P. (1948). Amer. 7. vet. Res., 9, 50.

Eden, A. N. (1962). 7. Pediat., 61, 33.

Elek, S. D. (1948). F. Path. Bact., 60, 183

Fletcher, R. D., and Plastridge, W. N. (1964), 7. Bact. 87, 352.

Hood, Marion, and Todd, J. M. (1960). Amer. F. Obstet. Gynec., 80, 506.

Jackson, J. F., Hinton, Patricia, and Allison, F. (1960). Amer. F. Med. 28, 986.

Jones, F. S., and Little, R. B. (1931). F. exp. Med., 53, 835, 845.

Kahler, R. L., and Sheldon, H. (1960). New Engl. F. Med., 262, 1218

Kiggins, E. M., and Plastridge, W. N. (1956). F. Bact., 72, 397.

Kilo, C., Hagemann, P. O., and Marzi, J. (1965). Amer. F. Med., 38, 962.

King, Elizabeth O. (1957). 7. infect. Dis., 101, 119.

1962). Ann. N.Y. Acad. Sci., 98, 700.

(1965). Personal communication.

King, Sylvia, and Bronsky, D. (1961). 7. Amer. med. Ass., 175, 1045.

King, Sylvia, and Bronsky, D. (1961).
Lecce, J. G. (1958). I. Bact., 76, 312.

Lecce, J. G. (1958). 尹. Bact., 76, 312. 1 . $18,243$.

Loeb, H., Bettag, J. L., Yung, N. K., King, Sylvia, and Bronsky, D (1966). Amer. Heart F., 71, 381 .

Loesche, W. J., Gibbons, R. J., and Socransky, S. S. (1965). F. Bact. 89,1109 .

MacFadyean, F., and Stockman, S. (1913). Report of the Departmental Committee Appointed by the Board of Agriculture and Fisheries to Enquire into Epizootic Abortion, Vol. 3. H.M.S.O., London.

Mandel, A. D., and Ellison, R. C. (1963). F. Amer. med. Ass., 185, 536

Mandel, A. D., and Ellison, R. C. (1963). 7. Amer. med. Ass.,

Middelkamp, J. N., and Wolf, H. A. (1961).

Park, R. W. A. (1961). F. appl. Bact., 24, 23

Peckham, M. C. (1958). Avian Dis., 2, 348.

Prévot, A. R. (1940). Ann. inst. Pasteur, 64, 117.

- (1948). Manuel de classification et de détermination des bactéries anaérobies, 2nd ed., p. 118 . Paris.

Reich, C. V., Heist, C." E., and Dunne, H. W. (1961). F. Bact., 82, 210.

Rhoades, H.' E. (1954). Amer. 7. vet. Res., 15, 630.

Ringen, L., and Frank, F. W. (1963). F. Bact., 86, 344.

Ritchie, A. E., Keeler, R. F., and Bryner, J. H. (1966). f. gen Microbiol., Ritchie, A. E., Keeler, R. F., and Bryner, J. H. (1966). F. gen Microbiol., Robin, L. A., Duprey, G., Jouannot, J. F., Paris, P., Magard, H., Mignard,J., and Berteau, P. (1962). Presse méd., 70, 321.

Smith, T. (1918). F. exp. Med., 28,701.

and Taylor, M. S. (1919). Ibid., 30, 299.

Spink, W. W. (1957). f. Amer. med. Ass., 163, 180.

Tunnicliff, R. (1914). F. infect. Dis., 15, 350.

Vinzent, R. (1949). Presse méd., 57, 1230.

Ward, B. Q. (1948). F. Bact., 55, 113.

Wheeler, W. E., and Borchers, J.' (1961). Amer. 7. Dis. Child. 101, 60

Wilson, G. S., and Miles, A. A. (Topley and Wilson) 5th ed., Vol. 1, 1964, Principles of Bacteriology and Immunity. London.

\title{
Case of Human Vibriosis
}

\author{
J. H. DARRELL,* M.B., D.C.H., M.C.PATH. ; B. C. FARRELL, $\dagger$ F.I.M.L.T. \\ ROSEMARY A. MULLIGAN, $\ddagger$ M.B., B.SC., M.R.C.P.
}

Brit. med. F., 1967, 2, 287-289

Vibrio fetus was first recognized as a cause of contagious abortion in cattle by MacFadyean and Stockman (1913). Vincent et al. (1947) first described the human infection. The remaining human cases have been reported almost exclusively in the American literature. We cannot find a report from Britain.

\section{Case Report}

A male Egyptian accountant aged 28 had no history of close or repeated contact with animals. Eighteen months ago he developed abdominal distension and attacks of fever of about three days' duration, recurring at monthly intervals. Six months later he was admitted to hospital in Cairo with hepatosplenomegaly, jaundice, ascites, and a tendency to bleed; active cirrhosis was diagnosed. In the past he had had schistosomiasis and gonorrhoea, both apparently adequately treated. On examination active cirrhosis was clearly

- Lecturer, Royal Free Hospital, London. Now at Department of Bacteriology, Postgraduate Medical School of London.

t Chief Technician, Department of Microbiology, Royal Free Hospital, London.

‡ Assistant Lecturer, Department of Medicine, Royal Free Hospital, London. present. On the night of admission he passed three loose pale stools and his temperature rose to $103^{\circ} \mathrm{F} .\left(39.4^{\circ} \mathrm{C}\right.$.). There was generalized abdominal tenderness. Specimens of blood, urine, stool, and ascitic fluid were obtained for culture. His W.B.C. count was 6,800 , with $63 \%$ neutrophils. Within three days his temperature returned to normal without specific treatment, the abdominal tenderness abated, but the diarrhoea persisted. Barium-meal examination showed a dilated proximal small bowel, but sigmoidoscopy revealed no evidence of colitis. No apparently pathogenic organisms were isolated except from the blood, which yielded, from two cultures, an organism subsequently identified as a variant of $V$. fetus, resistant to the penicillins, including ampicillin, but sensitive to tetracycline, chloramphenicol, and the streptomycin group.

He had previously received tetracycline on several occasions and was now given streptomycin $0.5 \mathrm{~g}$. four times daily intramuscularly, and chloramphenicol $2 \mathrm{~g}$. daily for eight days. Six days after admission, though afebrile and still on antibiotics, he developed consolidation at his right lung base and a pleural effusion. There were no signs of pulmonary embolism or subphrenic abscess. He complained of throbbing back pain, not clearly localized, which worsened over the next three days. His temperature had remained normal after the antibiotics were discontinued (Fig. 1), but now rose to $100^{\circ} \mathrm{F}$. $\left(37.8^{\circ} \mathrm{C}\right.$.). Penicillin and streptomycin gave only 